\title{
El trauma de los refugiados sirios en Kalimat de Helena Tornero \\ "El verdadero dolor es indecible. Si puedes hablar de lo que te acongoja estás de suerte" Rosa Montero ${ }^{(*)}$
}

\author{
Dra. Alia Heshmat Kasem \\ Dpto. de Lengua y Literatura Hispánicas \\ Facultad de Letras, Universidad de El Cairo
}

\section{Resumen}

Esta investigación estudia el efecto catártico de las palabras para los refugiados sirios y su representación en el teatro español contemporáneo. La obra Kalimat, eje de este estudio, se basa en los testimonios de los protagonistas, en los que narran sus sufrimientos en el campo de refugiados y su vida anterior. Asimismo, expresan sus deseos y sus miedos explotando las técnicas del psicodrama para representar a todo el mundo su tragedia y al mismo tiempo curarse de su propio trauma. De esta manera esta representación teatral tiene un doble sentido al pertenecer a dos tipos dramáticos: teatro testimonial y psicodrama. Por eso aplicamos los métodos de ambos teatros para analizar el trauma de los refugiados sirios en el campo escénico español.

\section{Palabra clave}

Psicodrama - catarsis - teatro testimonial -testimonios refugiados - emigración.

يتناول هذا البحث بالدر اسة التأثير التطهيري للكلمات لدى اللاجئين السوربين وتمثيل

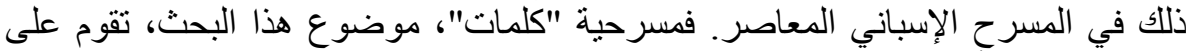
شهادات حية لأبطالها والتي يروون فيها عن معاناتهم في مخيم اللاجئين و عن حياتهم السابقة، ويستعرضون كذللك أمانيهم ومخاوفهم عن طريق استخدام تقنيات السيكودر اما ليمثلوا أمام العالم كله مأساتهم وليشفوا في الوقت ذاته من صدمتهم كلاجئين بعيدا عن فن

${ }^{(*)}$ Bulletin of the Faculty of Arts Volume 81 Issue 2 January 2021 
أوطانهم. وهكذا فان هذا العمل المسرحي ينتمي إلى نوعين مختلفين من الدراما المسرحية:

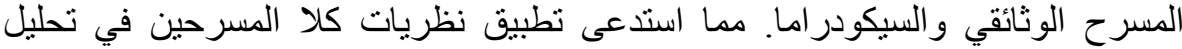

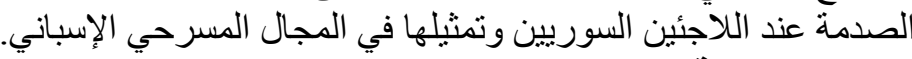

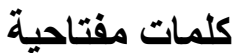

كلمات - سيكودراما ـ التطهر ـ المسرح الوثائقي ـ الثهادات ـ اللاجئين ـ الهجرة

\section{Introducción}

Helena Tornero es una dramaturga, directora, profesora y traductora de teatro. Ganadora de varios premios, entre ellos el Lope de Vega en 2015, funda junto a otros compañeros de profesión en 2016 Proyecto Paramythádes, una iniciativa artística dirigida a menores y jóvenes refugiados con el fin de darles la oportunidad de expresarse y crear su propia ficción. Uno de los frutos de este proyecto es la obra Kalimat, escrita y protagonizada por refugiados sirios en el campo Nea Kavala en Grecia. Kalimat representa los testimonios de cinco hombres y cinco mujeres sirios que viven allí

Asimismo, esta misma obra de Helena Tornero es elegida por El Teatro de la Abadía, para inaugurar su ciclo titulado Partir, venir, quedarse, celebrado en Madrid en el año 2017. Todas las representaciones de este ciclo tratan la miseria de los refugiados, desalojados y desterrados en diversos contextos y ambientes.

Kalimat pertenece al teatro testimonial español que no goza de suficientes estudios anteriores. En este sentido, el objetivo de este estudio es analizar cómo se sirve Helena Tornero, tanto de las técnicas del psicodrama como de las del teatro testimonial para representar el trauma y la memoria de los refugiados sirios es su obra Kalimat.

\section{La cura del habla}

Lo primero que llama nuestra atención en el análisis de cualquier obra literaria es su título puesto que, de manera más o menos implícita, deja entrever mucho del mensaje de la misma obra. La directora Tornero se da cuenta de la importancia de las palabras y los testimonios de los refugiados y utiliza al sinónimo árabe de las palabras como título de su obra. Según el diccionario de Jean 
Chevalier, "la palabra" tiene muchos símbolos. La palabra húmeda es como la esperma que penetra la oreja para fecundar el germen y crear el embrión, o la luz que penetra la tierra llevada por los rayos del sol. La palabra es una manifestación del amo del mundo (2012: 794). Chevalier cita la expresión de Maurice Leenhardt para afirmar la fuerza de cualquier término: "la palabra es un acto". Es la misma idea que asiente Jacob Boehme: "todas las lenguas, las fuerzas, los colores y las virtudes residen en el verbo o palabra” (2012: 795).

Para los griegos, la palabra no significa solamente el vocablo, la frase y el discurso, sino también la razón, la conciencia, la inteligencia, la idea y el sentido profundo de un ser: "La palabra es el símbolo más puro de la manifestación del ser que se piensa y expresa a sí mismo" (2012: 785) En este sentido, al escribir sus "Kalimat", los refugiados son los dueños de sus propias palabras y su propia historia. Sus palabras no son simplemente unos sonidos que causan ruido, sino que son sentidos percibidos y unas huellas dejadas en el mundo. Esto explica la razón por la cual Helena Tornero decide mantener el título de la obra en árabe, la lengua materna de los refugiados, afirmando la fuerza creadora de sus propias palabras.

Al tomar como punto de partida la importancia de la palabra y su papel catártico de las negativas emociones, Helena Tornero y sus compañeros animan a los refugiados a escribir una obra testimonial para expresar sus sentimientos y contar su historia.

De ahí que se pueda observar evidentemente el empleo de las técnicas del psicodrama fundadas por el psicólogo rumano Jacob Levy Moreno quien afirma que "el psicodrama pone al paciente sobre un escenario, donde puede resolver sus problemas con la ayuda de unos pocos actores terapéuticos. Es tanto un método de diagnóstico como de tratamiento" (1946: 177). Esto es lo mismo que hace Tornero con los refugiados en un intento de ayudarles en su miserable situación, con la pretensión de aliviar sus dolores y sus sufrimientos. 
Como los demás voluntarios que prestan apoyo a los refugiados, Tornero y su equipo encuentran que la mejor manera de ayudarles consiste en enseñarles unas formas escénicas para librar sus memorias y purificarse del dolor causado por su situación como refugiados. Las palabras emitidas por los protagonistas tendrán una enorme influencia aliviadora al remediar almas heridas y devolverles la esperanza perdida. Las emociones que pueden surgir de modo caótico a veces, a través de una furia colérica o una angustia, encuentran poco a poco las palabras convenientes para ser expresadas dando así a los refugiados una nueva expectativa en la vida después de un largo de tiempo de desdicha: "De nuevo sentimos que existimos, que estamos vivos. Aún hay esperanza" (2016: 58).

María Carmen Bello asegura: "El Psicodrama es así un método para coordinar grupos a través de la acción, creado a partir de y para los grupos humanos. Su cuerpo de teoría básico es la sociometría que puede ser definida como la ciencia de las relaciones interpersonales" (2000:24). Estamos ante un grupo de personas sin ninguna relación social, más allá del éxodo y sufrimiento compartidos en un viaje hacia una situación de seguridad y un futuro mejor. Se trata de un conjunto de individuos de diversas procedencias y clases sociales: los padres Mahmoud y Mariam con sus hijos pequeños; la viuda madre Shaenaz y sus dos hijos jóvenes Hussein y Manar; la madre Khamissa y su hija Fátima; los amigos jóvenes Baran y Ghadir y, por último, el joven actor Ahmed. A pesar de las condiciones tan diferentes de estos protagonistas, todos se unen en unas relaciones interpersonales a causa de la guerra que acaba con los planes que cada uno tenía tanto de su futuro como del porvenir de sus hijos. El motivo principal de las relaciones establecidas entre ellos consiste en buscar un medio de salvación del peor destino encontrado en su refugio. La solución de sus problemas se encuentra en sus vínculos y en la solidaridad que les facilita convivir en las amargas condiciones de su refugio.

Además de estas relaciones sociales y grupales hay otros 
aspectos que definen la obra del psicodrama, sus cinco herramientas esenciales: protagonista, escenario, yo-auxiliar, director/a o terapeuta y auditorio. A su vez, cabe destacar la existencia de cuatro fases diferenciadas entre sí: caldeamiento, dramatización y comentarios (2013: 322).

\section{El protagonista:}

Los protagonistas sirios desempeñan una doble función al ser los autores y actores de sus propias historias. Esta duplicidad de roles, tan característica del psicodrama, les permite a los refugiados exponer sus testimonios a partir de lo que creen o sienten. No existe intervención alguna por parte de otras personas que puedan contaminar el argumento con sus propias versiones de los sucesos, influyendo así en la historia de los protagonistas. La realidad de la creación de la obra con base en los testimonios de los sirios llama nuestra atención al nuevo papel desempeñado por el director de este psicodrama.

Para los protagonistas refugiados se hace muy significativo poder manifestar su condición injusta en un escenario, haciendo público lo que les está pasando. Abren una ventana para oxigenar los lugares donde han habitado durante largo periodo. Se trata de un intento de admitir que el dolor interior y la tristeza salgan hacia fuera con el objetivo de dejar paso a otros estados íntimos más enérgicos y tranquilizadores, llevando a cabo lo que Sigmund Freud llama "catarsis" cuyo origen se encuentra en Aristóteles, tal y como afirma Gustavo Figueroa (2013). Este aprovechó dicho término para especificar el propósito de la obra teatral declarando que podemos conseguir purificarnos emocional y mentalmente por medio de este mecanismo. También podemos librar nuestros propios problemas al involucrarnos en la trama e identificarnos con los personajes principales para reflexionar, sentir e incluso redimir nuestras propias luchas. Para Sigmund Freud y Joseph Breuer este método catártico se convierte en una técnica terapéutica mediante la cual se descubren los sentimientos escondidos por medio de la liberación de los recuerdos 
donde se ocultan muchos de nuestros problemas.

La influencia del teatro político de Piscator es notable en el expresionismo; es decir, al deducir que la realidad y la situación de los refugiados se puede desarrollar no en contextos y conflictos privados, sino desde el punto de vista de lo público y lo social (Herrer, 2007: 26). No se trata de los problemas personales de los protagonistas de esta obra en los campos de refugiados, sino que el tema va más allá, convirtiéndose en un motivo más típico y alegórico. Esto se debe a que el expresionismo presenta y trata a todos los individuos sin conocerlos de manera personal. No se habla de los diez refugiados sirios como personajes independientes que se enfrentan a sus propios problemas, sino que los representa como pueblo que resiste los desastres de la guerra. Lo que importa en este caso no es el individuo aislado, sino el mundo injusto en el que lucha: "Mariam: El barco está lleno hasta arriba de refugiados y de inmigrantes. Baran: A bordo hay gente procedente de más de quince embarcaciones" (2016:11). Los protagonistas no narran solamente sus propias aventuras, sino que describen unas circunstancias compartidas con los demás desplazados, convirtiéndose en símbolo de los refugiados de las distintas nacionalidades.

Los diez refugiados sirios representan la primera herramienta de las obras psicodramáticas, esto es, el protagonista. Configuran el elemento primordial del psicodrama, cuyo problema va a tratarse en el mismo. Sin ellos no existe psicodrama. Esta obra trata de un protagonista colectivo puesto que todos comparten por igual la tensión dramática. Entre todos se dividen por igual el texto dramático y la narración. Cada uno de ellos tiene su propio espacio para contar su historia desde su perspectiva que, a su vez, se entrecruza con la de los demás en muchos aspectos, sobre todo respecto al sufrimiento por el que pasa un refugiado y la separación de sus familiares.

SHAENAZ Oh, Dios mío. Qué situación tan difícil, ver aquel mar y aquella lancha de goma flotando allí delante. 
MANAR Muy duro. Ni un solo momento de descanso mental. Pasan mucho frío esperando en la playa, mucho frío durante tres días.

HUSSEIN Finalmente llega la hora del "viaje de la muerte". Sabemos que el peligro es grande. Nos horroriza tener que cruzar el $\operatorname{mar}(2016: 9)$.

A pesar de que cada uno posee la oportunidad de relatar su propia versión sobre su viaje como refugiado, se nota que los demás complementan sus palabras a través de la cooperación, incluso en cuanto a sentimientos se refiere.

Los personajes en esta obra son retratos realizados mediante el proceso de superposición de varios individuos de los que se eliminan los caracteres particulares y se conservan los rasgos más generales. Son personajes que proceden de distintas zonas de Siria: Ahmed viene de Tabka; los amigos Baran y Ghadir de Latakia; Mahmud y su mujer Mariam de Alepo; Shaenaz y sus hijos Hussein y Manar de Damasco y Khamissa y su hija Fátima de Quneitra. Esta diversidad afirma la idea de la fuerza unificadora del sufrimiento. Asimismo, se nota la diversidad de los oficios y la vida social y económica de estos protagonistas. Encontramos a los estudiantes que no pueden concluir sus estudios por culpa de la guerra como Ahmed, Baran, Hussein y Fátima. Incluso los que acaban su carrera universitaria, no pueden conseguir trabajo porque tienen que hacer el servicio militar e ir a la guerra. Paralelamente, están las amas de casa, Mariam- Shaenaz y Khamissa- cuya única preocupación consiste en el cuidado de sus hijos y mantenerlos lejos del peligro de la guerra.

Todos los personajes presentan una breve introducción de su vida en Siria, en la que notamos un conjunto de aspectos tanto sociales como económicos y políticos de los protagonistas, con el motivo de reflejar al espectador una imagen real de su situación antes del éxodo. Las palabras están cargadas de emociones, ya que su objetivo no es 
evocar la simpatía del público, sino representar al personaje del refugiado en una forma primitiva. La introducción es un recordatorio al público de que estos son seres humanos que tenían una vida normal antes del comienzo de la guerra como cualquier otra persona en el mundo.

\section{Yo-auxiliar:}

Dentro del grupo de estos sirios se encuentra otro aspecto fundamental del psicodrama, el yo-auxiliar, cuya función consiste en participar activamente en la representación dramática, con unos roles complementarios a los de los demás protagonistas, con el propósito de originar el ambiente conveniente emocionalmente para sus compañeros en el escenario. El actor Ahmed desempeña quince papeles muy distintos para auxiliar la transmisión de los testimonios dramatizados llevando a cabo el rol de los ausentes como, por ejemplo, los soldados del campo o los voluntarios que los visitan. Esta inversión de roles lleva a cabo una misión fundamental al facilitar ver los problemas y los personajes desde el punto de vista de los otros.

Cada vez que los refugiados cuentan una situación que requiere la presencia de algún personaje ausente, Ahmed expresa su voluntad de manifestar sus capacidades como actor desempeñando el papel necesario para que la situación sea representada de una forma completa y los problemas enfrentados sean transmitidos, no solamente al público del campo de los refugiados sino a todo el mundo.

HUSSEIN Tuve que llevar el féretro con el cuerpo muerto de mi padre muerto hasta la frontera. Mi tío me estaba esperando allí. Me dijo

AHMED “Espera. Tú no puedes entrar en Siria. Es muy posible que si entras, no te dejen volver a salir. No quiero más muertos en la familia”.

HUSSEIN Más o menos. No dijo eso exactamente.

AHMED Da igual. Estoy representando un personaje. Soy actor 
(2016:7).

En la primera intervención de Ahmed en la acción como yoauxiliar, sustituye al tío de Hussein en una situación muy trágica durante la entrega del cadáver del padre de este a su familiar para poder enterrarlo en Siria. La reacción del tío es crucial para reflejar la tragedia de los sirios que no pueden volver a su patria ni para asistir al acto fúnebre de sus padres. Para solucionar su ausencia en el escenario, Ahmed está dispuesto a representarlo para ayudar a su compañero Hussein en la transmisión de su difícil estado al estar impedido de enterrar a su propio padre. Además, Ahmed encuentra en estas situaciones una oportunidad para revelar a todo el mundo sus habilidades como actor. Así improvisa añadiendo sus propias palabras en la situación representada, en un intento de ganarse la admiración del público que asiste a la representación de la obra.

Aparte del papel del tío de Hussein a lo largo de la representación, Ahmed desempeña múltiples y diversas actuaciones, como por ejemplo los voluntarios que los ayudan y los militares que les dificultan la vida en el campo. Esta variedad de los roles atestigua su talento artístico y sus habilidades como actor profesional a pesar de que: "No pude acabar el curso, pero quiero ser actor profesional. Puedo interpretar cualquier personaje. Tú pídeme un personaje. Yo te lo hago" (2016:1). La guerra le impide perseguir su sueño, pero lo reencuentra de nuevo en este psicodrama en el que Tornero lo emplea como yo-auxiliar con el objetivo de desarrollar las historias de todos los refugiados. A través de esta técnica, la dramaturga aprovecha la disponibilidad de Ahmed y su entusiasmo de llevar a cabo cualquier papel para sustituir a los personajes ausentes y ayudar en la comprensión de la tragedia de los refugiados sirios.

\section{El escenario:}

El lugar que eligen los sirios y lo convierten en el escenario de su historia es muy significativo para ellos. El escenario se construye 
en un lugar junto a la escuela y el centro cultural que, teóricamente, desempeñan un papel importante en mejorar la vida de los refugiados. La elección de este lugar es acertada, tanto para el transcurso de la acción como para transmitir el tema de la obra, el cual debe resultar atractivo a todos los habitantes del campo. Tal elección tiene una función primaria que consiste en agregar viveza y certidumbre al proceso en un área escogida propiamente para esta sesión. Allí los protagonistas experimentan varias ideas electivas y pretenden diversas representaciones. Se forma así el laboratorio dentro del escenario, mientras que fuera llevan a cabo la misión de recopilación de los testimonios y procesarlos. Asimismo, este lugar público frecuentado por todos los refugiados del campo da vida y realidad a la acción de la obra, ya que es un lugar donde todas las vidas e historias de los refugiados se entrecruzan inconscientemente en su cotidiano. Así, el objetivo de esta obra es representar tales escenas reales ante sus verdaderos protagonistas para revivirlas, pero esta vez, de una manera totalmente consciente.

Blatner (2013) afirma que frecuentemente se forman en el psicodrama unas ideas nuevas que merecen "ir al escenario" de nuevo. Esto es lo que sucede con la tragedia dramatizada de los refugiados. Kalimat tiene dos escenarios, uno en el campo de refugiados y otro en Madrid. El segundo escenario se ubica fuera del campo para que los testimonios de los refugiados puedan llegar a muchas personas y su influencia traspase las fronteras de Nea Kavala y toda Grecia. "SHEINAZ Nos sugieren la idea de escribir lo que sentimos en el campo. KHAMISSA Dicen que nuestras palabras se escucharán en nuestro país, en un teatro. Quieren escuchar nuestro testimonio en primera persona" (2016: 58). El impacto del psicodrama así no se limita a los protagonistas dentro del campo de refugiados, sino que sus huellas llegan a gran cantidad de gente para ampliar el rango del mensaje de los testimonios dramatizados en esta obra. 


\section{Directora:}

Tornero como dramaturga de teatro testimonial, cumple una tarea de historiadora que se atreve a la formación de su composición a partir de un conjunto de conocimientos históricos intensivos. Entre tanto, no solamente busca exponer los sucesos, sino que revela también sus antecedentes, motivos y contextos. Su labor es descubrir el cómo y el porqué de los acontecimientos dramatizados. En otras palabras, se trata de mostrar la verdad de los acontecimientos y pretender transformarlos. Algo similar a lo que reclama Brecht en su técnica de distanciamiento según la cual el arte origina una realidad nueva y son los sucesos sociales los que manifiestan, sin la necesidad de la invención de ficticia realidad para hacer arte: "Distanciar significa colocar en un contexto histórico, significa representar acciones y personas como históricas, es decir, efímeras" (2004: 84). Esto es lo que hace Tornero al basar su representación en testimonios reales que no tienen nada que ver con las acciones imaginarias de otras obras teatrales.

La elección que realiza Helena Tornero refleja su experiencia en el trabajo del teatro testimonial, "con El Gallinero de Girona, trabajé con un grupo de adolescentes a partir de lo que vivieron sus padres cuando tenían su edad: la lucha democrática en la calle, la transición, la represión. De allí salió Primeras imágenes de Marte (Girona, 2012)" (2017). Además, enriquece su trayectoria teatral, que empieza en 2002, a través de otras composiciones teatrales basadas en los testimonios de unos adolescentes en Looking for happiness) (Teatro de Ponent, Granollers, 2011) y en Presente, pasado, futuro y otras historias de mi existencia (Mataró, 2014). Sin embargo, la obra Kalimat se distingue por sus "dimensiones difíciles de imaginar. Piensa que no son solo las condiciones de los campos: "esta gente viene de una guerra de una crudeza extrema. Y solo sabemos una pequeña parte. La información que nos llega está filtrada por muchos intereses ajenos" (2017). La dramaturga española, conmovida por las 
historias de los refugiados, a los cuales ella misma ve durante sus visitas al campo donde residen en Grecia, se ve obligada por su profesión dramática a divulgar a nivel internacional las difíciles condiciones de esa gente empleando sus propias palabras, llevando a cabo así la función del Teatro Político de Erwin Piscator, que pretende tomar parte con sus métodos dramáticos en la transformación de la realidad social y del hombre (1978: 8).

Helena Tornero explica en una entrevista el proceso por el que pasan estos refugiados para escribir sus testimonios:

Una vez hablamos con el TNC volvimos a Grecia para trabajar en la recogida de textos en la comunidad de refugiados. La idea era que narraran en primera persona su viaje hasta llegar a Grecia y el día a día en la vida del campo. Se hicieron ejercicios de escritura con ellos para que fueran encontrando su voz, algunos de más lúdicos, porque no debemos olvidar que la escritura sacude muchas cosas y están en una situación de mucha angustia y estrés. Están en una espera en condiciones infrahumanas, una espera que, además, no les ofrece ningún futuro (2017).

También los protagonistas describen tanto sus papeles como escritores del psicodrama como el de la dramaturga y su equipo: "HUSSEIN Escribimos una obra breve y la ensayamos durante toda una mañana. La obra la hacemos en árabe y en curdo, y ellos nos dirigen en inglés y en catalán, pero lo conseguimos" (2016: 54). A pesar de la diferencia de las lenguas entre los protagonistas y los voluntarios del teatro, logran realizar su representación testimonial sin que la lengua sea un obstáculo que imposibilite la transmisión del mensaje que todos quieren comunicar.

\section{El auditorio:}

El auditorio es esencial en toda representación dramática y también se considera significativo en el psicodrama. En este último caso, el público está constituido por los miembros del grupo de terapia 
y no se caracterizan por la pasividad, sino que reaccionan emotivamente hacia la escena. Los espectadores se conmueven con empatía al escuchar las experiencias de los refugiados y sienten los mismos dolores e inquietudes de los protagonistas compartiendo con ellos sus propias experiencias. "MAHMUD Decidimos representarla por la noche delante de la gente de Nea Kavala. El público llora. Nos aplauden con entusiasmo. Es una noche de celebración. Aquella noche decidimos crear nuestra compañía de teatro" (2016: 55). El éxito del psicodrama y su recepción con aplauso del auditorio dentro del campo les da a sus protagonistas la confianza y les anima a continuar su creatividad dramática, incluso después de la partida del equipo de teatro español.

Una oportunidad de compartir los sentimientos y las experiencias tiene lugar al finalizar la representación, en la cual participan todos los miembros del psicodrama: protagonistas, yo auxiliar, director y auditorio. Este instante está destinado a que todas las personas que asisten al psicodrama muestren sus propias emociones después de ver la exhibición de los problemas, pasiones, miedos y deseos ante toda la gente. De esta manera, se cumple un propósito importante que consiste en que los protagonistas refugiados no se encuentren solos al enfrentar su día a día y que sientan el apoyo y la comprensión de todos los demás, quienes también pueden expresar sus propios sentimientos.

Esta obra teatral no se basa en documentos oficiales de la Administración Pública que se realizan de acuerdo con la política del Estado, sino que son testimonios particulares de unos refugiados que documentan hechos por los cuales han pasado ellos mismos y, en muchas ocasiones, con los que siguen lidiando hasta el momento de la representación de la obra. Aunque estos textos no están certificados por ningún funcionario, el público tiende a preferirlos porque transmiten experiencias íntimas de unas personas con las que se pueden identificarse. 
Helena Tornero y su equipo observan esta buena acogida del psicodrama en el campo y pretenden ampliar el rango de su influencia fuera del campo:

MANAR Esta noche se hace una obra en el Teatro Nacional de Cataluña. En Barcelona. Una obra con nuestras palabras. Estamos muy nerviosos... Me gustaría estar allí. Me gustaría poder ver a los actores, sentarme entre el público, escuchar mis palabras en una lengua que no es la mía. Pero tendremos que mirarlo por internet. BARAN Me gustaría estar en Barcelona con todos mis amigos de Nea Kavala. Ver con ellos la obra y después bailar todos juntos para celebrarlo (2016:62).

Sin embargo, hay una diferencia notable entre las dos representaciones. La representación que tiene lugar en España es protagonizada por actores españoles, al contrario de la primera representación protagonizada por los mismos refugiados. Asimismo, la recepción del público español es diferente de la de los refugiados que comparten los mismos testimonios dramatizados en el psicodrama.

Por todo ello, tal diferencia en la recepción entre los dos auditorios es explicada por Helena Tornero: "La idea es que la gente salga con ganas de moverse. De moverse de verdad, no de poner cuatro frases bonitas en Facebook. Y sí, todos podemos hacer cosas. No hay que ir allí, aquí hay mucho por hacer. Cada uno, desde su lugar, puede hacer algo, por pequeña que sea" (2017). Uno de los objetivos esenciales de agrupar los testimonios y realizar esta obra teatral consiste en el papel conmovedor del teatro a su público para tomar acción, mejorar las malas condiciones de los refugiados y ayudarles en su crisis. De esta manera la simpatía del auditorio español debe ser sustituida por verdaderos esfuerzos para mejorar las condiciones de los refugiados y facilitarles una vida humana. 
El concepto del arte como fin y su utilización para reflexionar los sentimientos privados desaparece después de la Primera Guerra Mundial dando lugar a una nueva categoría de arte, cuyo concepto consiste en la protesta contra la realidad y la intervención transformadora del individuo sobre su situación (Massimo, 1978: 53). Los refugiados no deben aceptar su condición sino rebelarse contra ella y esforzarse para obtener un mejor devenir.

\section{Caldeamiento:}

El caldeamiento es la primera etapa del psicodrama en la que todos los protagonistas sirios se preparan para poder expresarse en una representación dramática. Se trata de animar a los refugiados a comunicar sus sentimientos en unas sesiones intergrupales de modo que los protagonistas lleguen a expresar sus verdaderas emociones a pesar de su negatividad. Como esta es la primera vez para los refugiados sirios de escribir una obra dramática, surge la necesidad de enseñarles las técnicas de escritura: "FÁTIMA Trabajamos con la gente de teatro haciendo ejercicios de escritura" (2016: 58). Los voluntarios dramaturgos quienes visitan el campo les enseñan los diversos modos literarios de formular sus propios sentimientos y manifestar sus difíciles condiciones de refugio.

En un ejercicio literario creado específicamente para preparar a los refugiados dramáticamente, los dramaturgos les piden que imaginen ser un árbol. Según Jean Chevalier, hay numerosas interpretaciones del "árbol", entre otras, es el eje del mundo, el árbol de la vida, el paraíso terrestre, la iluminación, la potencia, el árbol ancestro, el árbol social, la evolución continua y la vida del espíritu. El árbol es un símbolo de la vida en perpetua evolución, en ascensión hacia el cielo (1985:118). En este sentido, para los refugiados, el árbol puede representar la regeneración perpetua. Tal y como pierde el árbol sus hojas y las recupera otra vez, los refugiados han perdido su patria, sus seres queridos y sus trabajos. Sin embargo, de una manera u otra, los van a recuperar en el futuro. 
Es muy interesante la elección del "árbol”. Los refugiados que viven olvidados en un campo al margen del mundo, simulan ser un árbol, eje del mundo cuyos frutos dan la inmortalidad, el retorno al centro del ser, es decir, al estado edénico (pág.119). A pesar de haber perdido sus familias, el árbol les representa el crecimiento de la familia y la seguridad sobre un plano espiritual (pág. 124-125).

Esta práctica logra sacar de los protagonistas sus más íntimos sentimientos escondidos para así manifestarlos delante de toda la gente. Al convertirse en un árbol imaginario, todos los refugiados sienten una fuerza mayor debido a su nuevo estado irreal basado en la firmeza y la resistencia simbólica de los árboles:

Shaenaz: (...) No lo sé, ahora tengo fuerza...mis raices están bien arraigadas hasta el fondo de la tierra, tengo las ramas grandes y unas hojas muy brillantes...cuando cae la lluvia puedo sentir como el frío me atraviesa, pero cuando sopla la brisa y el sol me ilumina el calor vuelve a mis hojas y me vuelvo a sentir viva, me siento parte de la naturaleza (2016: 59).

Después de salir de su patria y dejar todos sus recuerdos allí, sin ninguna esperanza de recuperarlos de nuevo a causa de las dificultades de la guerra, la fase del caldeamiento realizada por los voluntarios logra recuperarles a los protagonistas sus perdidos afectos en la vida, su energía y su capacidad de ser productivos y útiles en sus comunidades. A través de parecerse a los árboles, los refugiados vuelven a sentir su valor y su importancia en la vida después de un largo periodo de desesperanza.

De esta manera sobresale la fase de caldeamiento en su misión de elaborar a los protagonistas, cuando los voluntarios del teatro eligen un signo muy simbólico que despierta en los sirios múltiples emociones positivas, y les devuelven la fuerza perdida debido a las difíciles condiciones del refugio. El árbol logra resucitar todas las memorias de los protagonistas para ser representadas en sus 
testimonios dramatizados en esta obra teatral. Así esta fase arregla muy bien el camino para la segunda, llamada dramatización, en la que los sirios actúan para mostrar sus propios sentimientos, miedos y deseos.

Los protagonistas notan la importancia dada por Tornero y su equipo al motivo catártico de sus palabras que expresan sus sentimientos: "KHAMISSA Entonces llegan dos personas del grupo de teatro que había venido anteriormente al campo. Dicen que quieren ayudarnos. SHEINAZ Nos sugieren la idea de escribir lo que sentimos en el campo. KHAMISSA Dicen que nuestras palabras se escucharán en nuestro país, en un teatro. Quieren escuchar nuestro testimonio en primera persona" (2016: 58).

\section{La dramatización:}

Una vez definidos los protagonistas, el escenario y la escena, la dramatización, eje principal del psicodrama, empieza a tener lugar para cumplir su fin de catarsis deseada, que es un acto de liberación del individuo respecto a todos aquellos aspectos no resueltos consigo mismo y que lo llevan a redefinirse y reconciliarse con las personas en conflicto. Al mismo tiempo se siente comprendido y apoyado por el grupo como representante de la sociedad (2013: 126).

Esta fase del psicodrama lleva a cabo esta función catártica por medio de una serie de técnicas encabezadas, en el caso de esta representación testimonial, por la redramatización del pasado. Los recuerdos de los refugiados sirios constituyen unas construcciones vivas que pasan por un proceso de reprogramación creando una práctica correctiva. Así el equipo voluntario del teatro insiste en incitar a la memoria de los protagonistas en los talleres de caldeamiento celebrados en el campo.

BARAN Hacemos ejercicios de escritura espontánea.

HUSSEIN A veces, las palabras que escribimos sin pensar nos inspiran más palabras. Recuerdo las palabras de un chico de catorce 
años que nos dejaron impresionados.

AHMED "Yo antes era persona, y ahora soy mafia. Yo quería venir aquí para estudiar, para ser médico, ingeniero o abogado. Pero ahora soy mafia porque me tratan como si fuera mafia. ¿Podré volver algún día a ser persona?" (2016: 54).

Las palabras de este chico que llaman la atención de los protagonistas, expresan abiertamente sus recuerdos y las transformaciones hechas en su alma y su personalidad a causa de su situación como refugiado y de las consecuencias derivadas de esta. La comparación entre la vida anterior y la actualidad revela el deterioro causado por el maltrato de los responsables del campo y los militares. La insistencia de estos en despreciar y ofender a los refugiados hace que estos se crean sus insultos como si sus palabras fueran verdaderas, olvidando su vida anterior y sustituyendo su personalidad previa a esta situación por otra peor, resultado de una situación de vulnerabilidad extrema. Al declarar estas ideas que descubren el lado más escondido del alma, los sentimientos están liberados por la catarsis. Sin embargo, este no es el eje de la cura de estas almas sufridas, sino que solamente fortifica este remedio, presentándoles un tipo de alivio (Blatnar 2013: 40).

El monólogo constituye uno de los recursos más empleados en este psicodrama, mediante el cual los protagonistas sirios expresan sus pensamientos sin la presencia de un interlocutor real que escucha. Se trata de un arte dramático utilizado para transmitir al auditorio las emociones y las aspiraciones de los refugiados mientras que se interrumpe la escena. Esta técnica se considera firme con este objetivo de exteriorizar y representar en escena el psicodrama para facilitar la toma de conciencia de los protagonistas y el reconocimiento de sus sentimientos o pensamientos. En el psicodrama se supone averiguar en la acción tanto los acontecimientos reales como las dimensiones de los sucesos psicológicos no planteados normalmente en las representaciones dramáticas convencionales, como, por ejemplo, los 
miedos que tienen los protagonistas. Vemos a los protagonistas expresando sus temores en la segunda secuencia titulada "Enero" en la que inician su viaje lejos de su patria:

MARIAM Tengo miedo de la muerte.

FATIMA Tengo miedo de la represión.

HUSSEIN Tengo miedo de la guerra.

MAHMUD Tengo miedo de ver morir a mis hijos.

SHAENAZ Tengo miedo de no poder volver nunca más a Siria.

BARAN Tengo miedo de fracasar.

KHAMISSA Tengo miedo del futuro.

GHADIR Tengo miedo de separarme de la gente que quiero.

AHMED Tengo miedo de que mi país quede arrasado.

MANAR Tengo miedo de lo que pueda pasar mañana.

SHAENAZ Tengo miedo del mar (2016:7).

Estas declaraciones de los miedos de los protagonistas en forma de breve monólogo les facilitan tanto a ellos mismos como al público, entender cuáles son los sentimientos que les aturden en su vida diaria dentro del campo. Mediante el psicodrama y sus propios monólogos, los refugiados sirios alcanzan un entendimiento más profundo de sus emociones y de los resultados de estas. Cada uno revela sus verdaderos sentimientos públicamente animado por el trabajo grupal sin tener vergüenza de los prejuicios de los demás. Todos los protagonistas empiezan a darse cuenta de sus propios pensamientos, sentimientos, motivaciones, conductas y relaciones vinculadas a sus miedos.

Después de expresar sus miedos, Helena Tornero utiliza la técnica de la proyección hacia el futuro, en la cual el director invita a sus protagonistas a imaginar una escena del futuro. Según Blatner (2013:37), la idea es mucho más compleja que el mero hecho de imaginar, se trata de "jugar" los deseos y sueños del protagonista. 
Podemos imaginar un futuro limitado, que es mejor para evitar ser herido, pero es bueno que el director pregunte: “¿Qué sería todavía más maravilloso imaginar?" Se anima al protagonista a atreverse a soñar nuevos sueños. "Atrévete a imaginar lo que quieres $\mathrm{y}$, al hacerlo, descubre que en realidad quieres más. No cierres un camino antes de lo que debes. A veces un poco de expansión e imaginación abre las cosas un poco más" (2013:38).

Cada uno de los refugiados expresa en un monólogo muy breve sus deseos muy simples que resumen los requisitos básicos de una vida humilde. Sus demandas no son exageradas sino todo lo contrario, se podrían cumplir en condiciones normales. El problema al que se enfrenta estos protagonistas es que su vida se circunscribe a unas situaciones extraordinarias donde se les obliga a dejar de soñar o tener unas grandes aspiraciones para ellos mismos o sus hijos:

"MARIAM Quiero vivir una vida feliz. MAHMUD Quiero que mis hijos tengan un buen futuro. AHMED Quiero continuar mis estudios de teatro. KHAMISSA Quiero vivir con mis hijos. BARAN Quiero que Siria vuelva a ser como era antes. HUSSEIN Quiero volver a ver una sonrisa en el rostro de mi madre. MANAR Quiero ver la tumba de mi padre. FÁTIMA Quiero volver a vivir en mi casa. GHADIR Quiero que se acabe la guerra en mi país. SHAENAZ Quiero volver a Siria y visitar la tumba de mi marido. Quiero volver a Siria y ver a mi madre y llenarla de besos. Quiero volver a Siria y llenar de besos las puertas y las paredes de mi casa" (2016:8).

\section{Denuncia política}

El teatro de Helena Tornero está influenciado por Piscator y Brecht, quienes contemplan el futuro en busca de una transformación profunda tanto en la vida política como en las estructuras sociales. En contra del condicionamiento social auténtico del teatro naturalista, surge el teatro político de Piscator y el teatro épico de Brecht para apoyar una nueva visión científica de lo real. Para ellos no es la 
estructura social, económica, política y cultural lo que le imposibilita al hombre transformar su destino, sino el hecho de tener que buscar diversas maneras para escapar de sus miserias y encontrar un mejor futuro. Esto es lo que hacen los protagonistas de Kalimat al huir de su país por rechazar las difíciles condiciones que amenazan sus vidas, y decidir buscar nuevas formas que les posibiliten conseguir la seguridad y la vida digna que merecen. Nada les obliga a cambiar sus decisiones de solicitar refugio en Europa, porque en este teatro no se representan como víctimas incapaces y condenadas a reproducir los mismos modelos de conducta en un mundo cerrado, sino que actúan en un escenario para descubrir los motivos de sus desgracias para, posteriormente, intentar cambiarlos.

MANAR El viaje es duro(...)Muy duro. Ni un solo momento de descanso mental. Pasan mucho frío esperando en la playa, mucho frío durante tres días.

HUSSEIN Finalmente llega la hora del "viaje de la muerte". Sabemos que el peligro es grande. Nos horroriza tener que cruzar el $\operatorname{mar}$ (2016: 9).

Pese a la dificultad del trayecto, todos insisten en llevarlo a cabo porque es la única solución para sus problemas y sus sufrimientos, rechazando someterse a las condiciones o convertirse en mártires de estas. De esta manera, los refugiados representados se ejemplifican como los protagonistas del Teatro Político al rechazar su realidad y no aceptarla como algo fijo e inmutable, creyendo en su voluntad para transformarla. Tampoco dejan que las órdenes de los dirigentes o las palabras de la gente les alejen de sus objetivos o que lleguen a su último destino en Europa "BARAN Por el camino todo el mundo nos dice que la frontera está cerrada, pero nosotros tenemos la esperanza de que la abrirán y no les hacemos caso" (2016: 14).

Con el propósito de llevar a cabo este cometido de transformación, la obra de Helena Tornero debe tener la capacidad de 
exhibir con claridad la naturaleza del proceso histórico representado en su obra teatral; esto es, el estatuto de refugiados de millones de sirios a causa de la guerra. A la dramaturga no le interesa ni la escenificación de personajes célebres ni de secciones de un definitivo período histórico. No obstante, lo que le concierne consiste en los testimonios de los refugiados y las implicaciones escondidas en ellos para el mundo en el que viven. Así, Tornero intenta exponer la realidad de una manera objetiva dependiéndose en las observaciones de los protagonistas, quienes ambicionan con llevar a cabo cambios sociales. De esta forma, la ficción de la obra teatral es sustituida por la realidad descrita en los testimonios de los refugiados mostrando el mundo tal como es con su feroz hostilidad y crudeza. Estamos ante una categoría de teatro testimonial que no cede a las condiciones tan miserables de los refugiados, sino que pretende representarlas de manera dura y extrema, con el fin de que esta exhibición tenga la capacidad de incitar significativas transformaciones sociales.

Se considera difícil analizar la obra Kalimat como parte del teatro testimonial sin observar algunas técnicas de la dramática brechtiana que están frecuentes en la estética testimonial. Ambos teatros poseen un valioso mecanismo de crítica y denuncia política. Los dos agrupan datos, documentos y testimonios para elaborar la trama por medio de sucesos históricos y reales, propagando una cierta interrogación sobre la conducta del entorno social y político y la literatura. Al igual que Brecht intenta materializar escénicamente la propuesta marxista atendiendo a la tradición de la literatura dialéctica, Tornero recurre a los recursos de este teatro, considerándolo como un arma para llamar la atención del público, con el objetivo de conducirle a rebelarse contra la injusticia y gastar su dinero en la Guerra, en un mundo en el que el individuo está inseguro en unas situaciones incomparablemente injustas.

Uno de los rasgos más fundamentales del teatro testimonial consiste en dilucidar y relatar las memorias más incómodas y 
escondidas en un lugar clandestino. Este carácter revelador resulta generalmente molesto para los dirigentes. Los testimonios narrados por los refugiados se consideran unos recuerdos personales encargados por amargura hacia su situación y revelar estas memorias en público lleva una cierta condena a los sistemas políticos que contribuyen en los sufrimientos estos protagonistas. Esta capacidad de despertar la conciencia se considera un respetable estímulo para producir unos cambios sociales, que no siempre resultan cómodos a los que procuran conservar el sistema político establecido. Esta obra de teatro testimonial presenta una propuesta para estimular el conocimiento de los motivos y razones por las cuales los refugiados sirios sufren injusticias y de esta manera intentar modificarlos: "MAHMUD: Alemania, Francia, Holanda, Inglaterra...me da igual. Un lugar donde haya paz y mis hijos puedan crecer hasta que podamos volver a casa." (2016: 13) Sus demandas son muy humildes y se limitan a garantizar una vida segura lejos de la guerra y sus desastres. No les importa el país de su destino a medida que esta nación les vaya cubriendo sus necesidades básicas.

También Brecht formula el distanciamiento en vez de la identificación como método de reflexionar en la que la cognición analítica aparezca con respecto a todo lo que se advierte o se observa. Sin embargo, esto no quiere decir que haya que renunciar a las emociones motivadas dentro del escenario, a medida que estos sentimientos estén bajo el dominio de un análisis crítico. De esta manera los espectadores no solamente deben sentir la empatía hacia los testimonios de los sirios y su sufrimiento, sino que tienen que poseer una visión crítica de todas las historias dramatizadas y formular su propio punto de vista hacia el caso de los refugiados y pensar en las diversas formas de auxilio en las que pudieran ser partícipes. Explotando la eliminación de las fronteras entre los actores y el público, como en el teatro épico, los espectadores toman conciencia y su participación en la representación se hace más activa, interviniendo 
de forma agente en el significado de la trama a la hora de comprender y relacionar sus diferentes partes (2013: 153).

Entre tanto, es imposible e insuficiente realizar un estudio sobre una obra del teatro testimonial sin observar el importante trabajo de Peter Weiss y su teatro, el cual desempeña el papel informativo que se debe llevar a cabo mediante los medios de comunicación. No obstante, estos no cumplen de la manera inicialmente esperada puesto que su tarea consiste en favorecer tanto a los sistemas políticos como a quienes los lideran. Asimismo, es un teatro crítico cuyo cometido es criticar el encubrimiento y el falseamiento de la situación política, social y económica. Es un medio de protesta pública que aparece como reacción frente a crueldades que deben ser declaradas y discutidas ya que funciona como un escenario político que sustenta la discusión de los diversos problemas políticos, económicos y sociales.

Dentro de las causas más importantes que motivan la elección de este tipo de teatro testimonial para dramatizar la historia de los refugiados sirios, encontramos la grave situación económica y política que padecen los protagonistas junto con el sufrimiento que llevan parejo al encontrarse lejos de su patria. Esta situación conllevaría una toma de conciencia politizada por parte de los espectadores. También las injusticias políticas y sociales de los refugiados impelen a que la autora, Helena Tornero, denuncie estas múltiples formas de represión contra los sirios a causa de la guerra y proponga cambios ante estas situaciones tan miserables. En un contexto social, político, económico y cultural tan injusto y pobre como el que sufren hoy en día los sirios en los campos de refugiados, resulta de gran importancia practicar e incitar la aparición de un juicio crítico que ayude a detener de alguna manera esa crueldad. De esta forma el teatro puede desempeñar el papel de denunciar las injusticias y combatirlas; rechazar la indiferencia y la inconsciencia de aquellos políticos, empresarios y medios de comunicación que se esfuerzan en su día a día por ir en contra del progreso de la humanidad: 
MARIAM Es bonito ver a los niños ir contentos a la escuela. Ayuda a hacer más soportable esta situación. Pero no puedo evitar pensar que si esta escuela existe es porque ni los gobiernos ni las grandes organizaciones están haciendo bien su trabajo. ¿Qué hace la Cruz Roja? Si te pones enfermo, nada más te dan aspirinas o un jarabe para la tos. Una cosa simbólica. Tenemos un montón de cepillos y pasta de dientes, pero no tenemos medicamentos. Ha habido una epidemia de hepatitis. Algunos niños han tenido que ser trasladados al hospital.

KHAMISSA El hospital está a una hora de distancia. Eso quiere decir que la ambulancia tarda una hora en venir y otra hora en llegar al hospital.

MARIAM Preguntamos en la Cruz Roja: ¿Por qué no hay una ambulancia en el campo por si hay una emergencia? En este campo hay muchas personas. /

KHAMISSA Nos dicen que no disponen de ambulancia porque "su tarea no es ambulatoria". ।

MARIAM ¿Qué clase de respuesta es esta? ¿Y cuál es su tarea? ¿Dar aspirinas? A partir de las cinco de la tarde, la Cruz Roja se va.

KHAMISSA Mejor que no te pase nada a partir de esa hora.

MARIAM Y cuando por fin consigues ir al médico, te dan unas recetas muy extrañas. Como si no fuesen conscientes de la realidad que estamos viviendo. A un amigo nuestro, el médico le recetó que se pusiera hielo encima de la mano. ¿Hielo? ¿Has visto tú alguna nevera en este campo? ¿De dónde quieres que saque el hielo en este desierto, eh? (2016:49).

Una de las técnicas empleadas por Helena Tornero, prestada del teatro brechtiano, consiste en el uso del distanciamiento mediante la ruptura de la cuarta pared encargada de acordarse interminablemente al público, que está asistiendo a una obra de teatro cargada de componentes extraídos de la realidad. La estructura de la 
representación teatral rompe las unidades dramáticas de Aristóteles y pretende suscitar la reflexión crítica. Kalimat se representa dos veces, la primera en el campo de Nea Kavala en Grecia por los mismos refugiados y la segunda en España por unos actores profesionales, entre los que está Ahmed Alhamso, el único de los refugiados que logra llegar a España y vivir en Barcelona, donde empieza a estudiar teatro. En ambas escenificaciones, Tornero recurre al trabajo actoral desde el enfoque del actor-narrador, en el cual los actores llevan a cabo el papel de los narradores de la historia de los refugiados. Se trata de una crónica, considerada como la forma más perfeccionada del teatro épico de Brecht y conformada por escenas ordenadas cronológicamente, pero dispersas en lugar para narrar el fatigoso viaje de los protagonistas a partir de su decisión de dejar su país.

HUSSEIN Nos fuimos de Siria el catorce de abril del 2013.

MARIAM Nos fuimos de Siria el veinticinco de octubre del 2013.

AHMED Me fui de Siria el veinticinco de noviembre del 2013.

KHAMISSA Me fui de Siria el quince de febrero del 2015.

GHADIR Me fui de Siria el diez de octubre del 2015.

BARAN Me fui de Siria el veinte de noviembre del 2015 (2016: 6).

Todos los datos del viaje de los refugiados están convertidos dramáticamente en acontecimientos fundamentales desarrollados y condensados linealmente. La capacidad tanto de los sirios en contar su trayecto convierten las aventuras y las miserias de unos años (para unos como Mariam y su familia) y unos meses (para otros como Khamissa y sus hijas), en una representación de trece secuencias donde se encierran diversos componentes históricos, transformándose de esta forma la obra en una extensa crónica teatral a través de la cual se intenta transmitir a los espectadores una idea del difícil camino que han tenido que recorrer hasta llegar a la actualidad.

La simplificación de los detalles no afecta en los momentos fundamentales contados por los protagonistas. La estructuración del 
texto en unas secuencias narrativas básicas es particularmente llamativa puesto que revela una exposición lineal del éxodo de los protagonistas a partir de su decisión de abandonar su patria, al tiempo que plantea una serie de cuestiones dramatúrgicas que remiten al tratamiento de una realidad histórica concreta.

Secuencia 1: 0. Antes

Secuencia2: 1. Enero (Turquía.)

Secuencia 3: 2. Febrero (Turquía-Grecia.)

Secuencia 4: 3. Marzo (Atenas-Tesalónica-Policastro)

Secuencia 5: 4. Abril (Nea Kavala.)

Secuencia 6: 5. Mayo (Nea Kavala / Idomeni/Macedonia.)

Secuencia 7: 6. Junio (Nea Kavala)

Secuencia 8: 7. Julio (Nea Kavala)

Secuencia 9: 8. Agosto (Nea Kavala)

Secuencia 10: 9. Septiembre (Nea Kavala)

Secuencia 11: 10. Octubre (Nea Kavala)

Secuencia 12: 11. Noviembre (Nea Kavala)

Secuencia 13: 12. Diciembre (Nea Kavala)

Esta linealidad cronológica nos revela un aspecto fundamental en el análisis dramático de esta pieza testimonial. Las fuentes de este texto y su posterior manejo nos permiten observar el tratamiento dramático condensador por parte de Helena Tornero. Los testimonios acerca de la realidad que viven los refugiados sirios nos ofrecen una visión colectiva de los detalles que representa la dramaturga en su obra teatral y la manera por la que los convierte dramáticamente en un desarrollo de los hechos fundamentales, concentrados linealmente.

El trabajo del Teatro Documento de Peter Weiss ofrece un conjunto de crítica de grado diverso. En primer lugar, viene la crítica del encubrimiento; esto es, las noticias emitidas en prensa, radio y televisión. Al analizar los testimonios dramatizados en Kalimat se 
observa una clara condena a los medios de comunicación tan orientados siempre a estar de acuerdo con los puntos de vista del grupo dominante, en este caso, los militares que dirigen el campo de Nea Kavala.

HUSSEIN Le pedimos que detengan la pelea antes de que tenga consecuencias trágicas.

MAHMUD “¿Qué? ¿No piensa intervenir?” No se digna ni a mirarme a la cara.

AHMED "Yo no soy responsable de lo que pueda pasar, que se maten entre ellos. Yo estoy aquí para proteger a los militares y a su equipamiento."

\section{MAHMUD Pero/}

AHMED "Si tienes miedo quédate aquí, detrás de mí, o vete a tu tienda. Lo que le pueda pasar a esta gente no es responsabilidad mía."

MAHMUD Esto es de muy poca humanidad, ¿no cree? ¡Su función es la protección de las personas, no mirar desde fuera!

AHMED “iMe importa una mierda lo que os pase, y a mi gobierno también!”

MAHMUD “'Sabe que conseguirá con esta actitud? ¡Que mueran personas!"

AHMED "Me da igual. Si muere alguien, lo repatriarán a Siria y listo."

MAHMUD "Muy bien. Muchas gracias. Disculpe por haberle hecho perder tanto tiempo. ¡Adelante! ¡Haga fotos! ¡Comunique estos hechos tan agradables a los medios de comunicación! iInfórmeles bien de estas vacaciones humanitarias que estamos viviendo y de su contribución convirtiendo a refugiados en bestias salvajes!" (2016: 23). 
Los refugiados representan de modo dramático en sus testimonios las situaciones que desnudan la verdadera actitud del ejército griego hacia ellos. Ahmed, quien aspira ser actor, desempeña el papel del militar griego que nunca muestra ni el más mínimo ápice de esfuerzo para parar las peleas que tienen lugar entre los refugiados. Al interpretar este papel, el refugiado sirio manifiesta ante el público los verdaderos intereses de los soldados en el campo, protegerse a ellos mismos y no a los refugiados. Además, provocan luchas internas entre los refugiados con el propósito de publicar sus noticias en los medios de comunicación, cuya única fuente de información reside en los soldados del campo de Nea Kavala.

Esta obra testimonial ofrece una representación de materiales verdaderos sin realizar ningún cambio en el contenido con el propósito de exponer unos procesos sociales e históricos. De esta manera, se puede considerar como una parte del teatro político puesto que pretende inculcar una formación política en el público. Asimismo, procura llevar a cabo una cierta influencia en la realidad y las condiciones de los refugiados por medio de la crítica a las mentiras de los dirigentes, los soldados del campo y los funcionarios de ACNUR, así como por el encubrimiento y falseamiento de la realidad de los medios de comunicación. Por otra parte, los testimonios de los protagonistas revelan los círculos que sacan provecho del encubrimiento y las falsas noticias de las condiciones de los refugiados. Los medios de comunicación no transmiten la realidad, sino que la modifican para que dirigentes políticos y militares obtengan beneficios $\mathrm{y}$, por ende, se idealice su función en los campos de refugiados. De este modo, se les representa como aquellos que mantienen el orden y la seguridad mientras que los refugiados son quienes provocan los problemas dentro del campo.

Los soldados provocan las disputas entre ellos para, posteriormente, permanecer impertérritos ante tal situación que, a su vez, la catalogan como muy divertida: 
MAHMUD Y los soldados, antes de que la gente se despierte, se dedican a dejar las latas allí, en medio del camino, para que la gente se pelee para conseguirlas.

BARAN Y ellos miran.

MAHMUD Miran y hacen fotografías.

KHAMISA Nunca me hubiera podido imaginar que llegaría a ver una cosa así. Ver hasta qué punto puede llegar la decadencia moral de las personas.

GHADIR En la tienda donde distribuyen ropa, los militares se ocupan de la repartición, pero, según dicen, no son responsables de organizar a la gente (2016: 21).

Los responsables militares insisten en transmitir a los medios de comunicación una falsa imagen de lo que pasa dentro del campo. Esto nos lleva al segundo tipo de crítica que intenta representar el teatro testimonial; la crítica de los falseamientos de la realidad. Los militares griegos engañan y fingen una falsa situación, en la que protagonizan el papel de los defensores de los derechos de los refugiados, con el propósito de defender su propia posición mediante la eliminación de acontecimientos y la inclusión de otros. Son estos dirigentes militares quienes obtienen beneficios de la deformación consciente de las situaciones que se suceden en el campo de Nea Kavala. Aquí se manifiesta el papel del teatro testimonial para criticar las falsificaciones tan aceptadas por todo el mundo como la verdad.

Este falseamiento de la realidad lleva consigo una serie de mentiras emitidas, en primer lugar, por los militares que llevan a un mayor engaño histórico. Este consiste en mostrar una falsa idea de los refugiados y representarles ante el público como salvajes e inhumanos. Notamos en los diálogos de los sirios y sus testimonios una crítica de mentiras declarando las repercusiones de estas falsedades en su vida diaria dentro del campo, o convertida en una tortura permanente a la espera de que se les ofrezca una salida. Tanto 
los órganos influyentes como los grupos de poder hacen lo posible por imposibilitar el descubrimiento de la verdad con el objetivo de mantener su imagen internacional como protectores de los refugiados y defensores de sus derechos, cuando en realidad son los primeros violadores de estos derechos, hasta que muchos "abandonan el campo definitivamente para proteger a los niños y las mujeres. $Y$ todo por la estupidez de un hombre cualquiera. Es verdad que no pasa un día en el campo sin que no haya algún problema, pero esta vez es mucho peor, más grande y más aterrador. Y ni el ejército ni la policía griega quieren intervenir." (2016: 24)

Entre tanto, la mayor ocupación de los militares del campo consiste en "hacerle el trabajo a la prensa racista y difundir fotografías mientras ellos no mueven ni un dedo." (2016: 24) Impidiendo cualquier tipo de comunicación entre los refugiados y la prensa, los soldados se convierten en la única fuente de noticias que llegan sobre la situación en el campo porque "el gobierno prohíbe la entrada a los medios de comunicación. Nada más entran, acompañados de un militar, los medios estatales, que no transmiten las preocupaciones ni las necesidades de la gente." Todas las partes saben que "Todas sus palabras son mentiras." (2016: 24)

El verdadero motivo de la prohibición de los medios de comunicación de entrar en el campo es visible en los testimonios de los refugiados que declaran las situaciones allí y los insultos recibidos por los militares:

AHMED "Piso, malaka!"

BARAN Al principio no entendemos lo que dicen.

AHMED "Piso, malaka!"

GHADIR Dicen eso y luego se ponen a reír.

BARAN Con el tiempo nos damos cuenta de que nos están insultando (2016: 18). 
Los soldados aprovechan el hecho de que los sirios no entienden el idioma griego y los insultan aumentando su miseria, arrebatándoles su dignidad y el derecho a una vida humana. Esta condición inhumana se ve aumentada por la falta de los requisitos primitivos de la vida humana. Tanto la comida y la bebida como los servicios sanitarios facilitados en el campo no cumplen el nivel básico de las condiciones humanas:

GHADIR Cada día que pasa estamos más indignados con esta comida infame que no nos sacia ni nada. Otra vez macarrones blancos, sin nada más. Me cabreo como un mono y voy al lugar donde hacen el reparto. El oficial responsable del reparto está plantado como un poste, mirándonos con el desprecio de quien mira a un esclavo. No sonríe nunca y su voz es tosca. Abro la caja de los macarrones y se la planto allí delante. Hablo con él en inglés. (Pero para vosotros lo haré en castellano.) “QQué se han creído, con esta comida? ¿Eh?”

AHMED “ ¿No te gusta la comida?”

GHADIR “¿La quiere usted? ¿Quiere probarla?”

AHMED "No. No quiero probarla."

GHADIR "Gracias. Ahora ya tengo la certeza de que no es comida para personas. Ni siquiera para los perros." (Pausa.) Me mira con rabia. Sabe que lo que le acabo de decir es la pura verdad. Tiro toda la comida por el suelo y me voy corriendo hacia mi castillo fortificado: esta fantástica tienda militar que ya se ha convertido en una fortaleza donde día tras día perdemos la esperanza de poder escapar (2016: 19).

En cuanto a los funcionarios de ACNUR, encargados de facilitar a los refugiados su estancia en los campos y proporcionarles la ayuda básica para unas condiciones de vida mínimamente dignas tampoco cumplen su tarea y dificultan la vida de los sirios entregándoles datos falsos en vez de los verdaderos con el propósito de obtener el 
beneplácito del gobierno griego:

GHADIR Buscamos al funcionario de ACNUR. No lo encontramos.

BARAN Preguntamos a otros funcionarios por nuestro expediente.

GHADIR No nos dan ninguna respuesta clara.

BARAN Finalmente, uno de ellos nos dice que nuestros nombres han sido borrados.

GHADIR Vemos al funcionario de ACNUR que nos atendiól

BARAN Ya lo han entendido.../

GHADIR Le acompañan una niña y un señor alto.

BARAN Se sorprende un poco cuando le paramos en medio de la calle. Nosotros no le damos importancia y empezamos a hablar sin darle tiempo a reaccionar. I

GHADIR ¿Qué ha pasado con nuestros nombres? Ha pasado un mes y nadie nos ha informado de cuándo será la entrevista. Y tú ya no pasas por el campo. ¿Qué ha pasado con el programa?

BARAN Nos mira con lástima.

AHMED "Es cosa del gobierno griego."

GHADIR No lo entiendo. ¿Qué tiene que ver con esto el gobierno griego? (2016:27).

La verdadera ayuda viene no de los responsables políticos o administrativos sino de los voluntarios, quienes se ven obligados a ofrecerles ayuda por motivos humanos:

GHADIR Estamos cansados y hambrientos después de otro día agotador. Solamente tenemos las latas que nos ha dado la voluntaria griega. Cogemos una bolsa de plástico, la abrimos en el suelo y nos sentamos en la vía del tren. Abrimos las latas directamente sobre la 
bolsa de plástico y empezamos a comer con las manos (2016:14).

El valor del teatro testimonial reside en su capacidad de presentar unos hechos y dejar que el público saque sus propias conclusiones e ideas de la representación a la que ha acudido. Expone las diversas acciones que representa el beneficio para una parte y el perjuicio para la otra. Ambas partes se enfrentan mostrando los logros de los vencedores y las pérdidas de los vencidos. Al obtener la victoria, los primeros se defienden, presentándose como protectores del orden. Al contrario de ellos, están los que pierden. Los refugiados se escenifican junto con los soldados y los funcionarios de ACNUR, quienes no les prestan ningún apoyo, sino que dificultan las circunstancias de su residencia en Nea Kavala.

Se escenifican unas perspectivas de desigualdades resumidas de forma que resultan inaguantables. Las injusticias que padecen los refugiados sirios se presentan de una manera tan decisiva que requieren una intervención urgente. Estamos ante unas situaciones muy grotescas, tanto que solo se pueden modificar con la fuerza y sin recurrir a las autoridades. Nadie logra cumplir con sus promesas de mejorar la vida de los sirios en el Campo de Nea Kavala, por eso se ven obligados a cruzar la frontera de manera ilegal en un intento de llegar al sueño europeo y encontrarse allí con sus familiares:

KHAMISSA Algunas familias deciden volver a Turquía a través de las mafias.

BARAN Otros se plantean cruzar Macedonia. (Gesto a Ghadir.)

GHADIR ; Y aquí es cuando decidimos cruzar Macedonia a pie!

TODOS Cruzar la frontera. Primer intento (2016: 29). A pesar de que esta obra testimonial presenta las diversas perspectivas, se considera partidista puesto que nos conduce a una cierta condena hacia los dirigentes del campo y los políticos quienes causan la miseria de los refugiados. La objetividad aquí se convierte en un concepto utilizado por la gente que tiene el poder para justificar 
sus acciones. Los episodios de agresión cometidos en el campo de refugiados solo se pueden mostrar como transgresiones unilaterales. Es solamente permitida la técnica del dibujo en blanco y negro en la descripción de las guerras y los ataques, sin reflejar el menor grado de condescendencia en el bando de los agresores, y con el mayor grado de solidaridad en el bando de los agredidos.

Un cierto surgimiento de la música y su papel esencial en la dramatización de los testimonios de los sirios quienes declaran la gran influencia realizada en sus almas con la llegada de los músicos voluntarios: "KHAMISSA Hacen actuaciones musicales con su orquesta. Se encargan de organizar actividades de teatro para niños y jóvenes. Organizan un grupo de yoga y danza para mujeres en el "Women's space" (2016: 54). También los protagonistas expresan la energía positiva de la música tan capaz de llevarlos a su patria de nuevo para que puedan recordar las buenas memorias que tienen de sus familias y sus hogares allí: "ponemos música y bailamos juntas. La música me transporta de nuevo a Siria. Recuerdo como me gustaba bailar. Como me gustaba vivir con mi familia" (2016: 54). De esta forma se observa el efecto de distanciamiento de la música en la vida de los protagonistas, donde se realiza una cierta transformación y un alejamiento de la miseria del campo una vez tocada la música.

Al igual que en el teatro épico, se nota la influencia relajante de la música que interrumpe el discurso escénico para cumplir con su armonía y ritmo; el doble cargo de situar a distancia la tragedia dramatizada y contribuir de manera didáctica en la reflexión de los testimonios de los refugiados. La música del violoncelo lleva a cabo su función de distanciamiento entre los espectadores y los discursos de los protagonistas con el fin de transmitir un papel didáctico y clarificar la situación dentro del campo de los refugiados sin provocar su simpatía hacia estos. Se describen las condiciones y los sufrimientos de los sirios, dejando al público la misión de valorar y racionalizar la realidad de lo que le ha sido transmitido. Con el objetivo de llevar a 
cabo esta tarea, debe alejarse del ambiente de la representación en escena por medio del efecto de distanciamiento.

\section{Mitificación de los testimonios}

Como resultado de la integración de diversos elementos escénicos, Tornero mezcla también los testimonios de los refugiados con unas estrofas elegidas de la Divina Comedia de Dante, dramatizando las historias de los diez refugiados y dándoles una índole mítica extraída de esta composición literaria. Al principio de cada escena, se incluyen unos versos de algún canto del Infierno o Purgatorio de la Divina Comedia, haciendo alusión a las difíciles condiciones en las que viven los refugiados y sus sufrimientos para sobrevivir en el campo de Nea Kavala.

Uno de los primeros aspectos de la influencia de Peter Weiss en Helena Tornero se observa en el uso de los cantos de La Divina Comedia de Dante, los cuales son el punto de partida de la obra documental más importante del escritor alemán: La indagación (1965). Esta obra teatral, que desarrolla el juicio de Auschwitz que sucedió en Frankfurt. Es un oratorio en once cantos inspirados en los dantescos, a través de los cuales Weiss denuncia al nazismo y sus crímenes. Sin embargo, lo que procuraba Weiss era dar "la vuelta a la idea -indiscutible para Dante- de que los buenos eran premiados y los malos castigados. En la realidad los malos casi nunca son castigados, ni los buenos premiados. En consecuencia, el Infierno debía ser un lugar de buena vida para los tiranos, el Paraíso un lugar de desesperación para los sufrientes" (Arias: 2006:100).

De esta manera surge la distinción tan obvia entre las clásicas metáforas de Dante y la realidad dramatizada en Kalimat que rechaza representar el campo de refugiados como un infierno simbólico. Tampoco surge la referencia al paraíso como lugar alegórico, en el que el bien consigue su recompensa. Nea Kavala puede ser considerado como un infierno real o como la expresión más esencial 
de lo que lo real puede tener de infernal cuando permanece libre de cualquier vínculo imaginario. Lo que sufren los protagonistas en esta obra no es algo simbólico sino trágico, por lo que la dramaturga no puede representarlo de manera alegórica, sino que está obligada a dramatizarlo de forma directa: "BARAN... La escuela es el único lugar donde podemos desahogarnos. Allí dentro nos sentimos los amos del mundo entero. Pero fuera, el infierno continúa" (2016: 48).

Una cierta concordancia se observa entre los versos mencionados del Infierno y los testimonios de los diez sirios: Ahmed, Fátima, Ghadir, Khamissa, Shaenaz, Bakher, Mahmud, Manar, Hussein y Maryam; incluso, se puede considerar como una parte de sus propias palabras porque describen unas situaciones similares a las que pasan los protagonistas en el campo de refugiados. Al principio de la obra, en la secuencia titulada (0 Antes), Tornero introduce las palabras de los refugiados sirios en las que describen su vida anterior a la guerra:

Y como quien, con hálito afanado

sale fuera del piélago a la riba,

y vuelve atrás la vista, aun azorado;

así mi alma también, aun fugitiva,

volvió a mirar el temeroso paso

del que nunca salió persona viva (2016: 4).

Estos versos se perciben como un resumen de las dificultades a las que se enfrentan los refugiados en su patria, las cuales les obligan a tomar la difícil decisión de dejar sus propias casas:

KHAMISSA: (...) Los jóvenes desaparecian mientras volvían de la universidad. Con el tiempo, las organizaciones terroristas fueron aumentando en las provincias sirias. Pero gracias a Dios, en la provincia de Quneitra aún estábamos tranquilos. Al principio del año 2013 empezaron los problemas en los pueblos de al lado. Cada día era peor que el anterior. El gobierno empezó a llamar a los jóvenes a la guerra. Querían que tomaran las armas. 
FÁTIMA Mi hermano fue el primero en desertar.

KHAMISSA Se fue a Alemania. Cuatro meses más tarde su otro hermano se fue al Líbano. Cuando nos avisaron de que el resto de mis hijos también tenían que ir a la guerra, decidí enviarlos también a Alemania. Solamente quedó mi marido. Pero el gobierno ya no tenía bastante con los hombres jóvenes. Se empezó a reclutar de forma caótica a todos los hombres disponibles del país. Y mi marido también tuvo que irse.

FÁTIMA Les amenazaban. Les llamaban a filas y les obligaban a tomar las armas. Mis hermanos no estaban de acuerdo y huyeron. Solamente quedamos las mujeres de la familia. Tuvimos que irnos trasladando de un pueblo a otro. Cuando la guerra se acercaba, nos íbamos.

KHAMISSA Una noche entraron los hombres del gobierno y me amenazaron. Me dijeron que se llevarían a mis hijas a la cárcel. Que las tendrían allí como rehenes hasta que mis hijos volvieran para cumplir con su obligación como soldados (2016: 5).

De la misma manera que Dante escapa del Infierno en su composición, los protagonistas sirios huyen del horror de la guerra en su país. La diferencia entre ambas obras literarias reside en la entidad del infierno representado. Al contrario del infierno alegórico poetizado por Dante, en el que los torturados son solamente los malos mientras los buenos son salvados, los testimonios de los refugiados representan un infierno real que no diferencia entre la gente basándose en sus pecados. Todos los sirios sufren no a causa de sus culpas sino por su ascendencia y su nacionalidad.

Estamos ante un documento en el que la dramaturga española explota los cantos de la Divina Comedia con el objetivo de realizar unas correlaciones entre los personajes, los espacios del infierno dantesco y los testimonios de los refugiados. Los políticos y los oficiales del ejército no son nada más que los empleados infernales de Dante. Mientras víctimas sirias se asimilan a las almas penitentes, descubren así en los versos dantescos el sentido simbólico que se aleja del límite exacto del texto y que es preciso para verificar su actualidad en el mundo contemporáneo. De esta manera Tornero consigue acortar la distancia que separa su composición del texto de Dante 
"sometiendo los contenidos originales a continuados procesos de resignificación alegórica, de modo que hereda del propio Dante Alighieri la actitud hermenéutica con la que el mundo medieval logra recuperar gran parte de la tradición literaria pagana a través de una relectura alegórica cristianizante o moralizante de los textos de Homero, Virgilio u Ovidio" (2018: 188-189). El sentido del Infierno queda en la vida de los refugiados a pesar de sus múltiples intentos de huir de él tanto en su patria como en su trayectoria hacia el "paraíso europeo" donde deben encontrar la seguridad y la humanidad perdida.

No obstante, el infierno terrenal en Kalimat es peor que el infierno imaginario descrito en la Divina Comedia. Si Dante logra salir del Infierno para ir al Paraíso pasando por el purgatorio, los refugiados sirios salen del infierno de la guerra de su patria creyendo que encontrarán una mejor vida fuera. El purgatorio de los refugiados no es nada más que una continuación del infierno experimentado en Siria. El horror y el sufrimiento que experimentan en su trayectoria para llegar a su destino en Europa, no se reducen, sino que se aumentan cada vez más, como si el destino de estas víctimas fuera la tortura y la desdicha que les acompañan a lo largo de toda la obra.

\section{Conclusiones}

La decisión de llevar a cabo un análisis sobre la obra Kalimat de Helena Tornero está apoyada en un particular interés por una dramaturgia que exhibe temas que por lo general permanecen enterrados en el lugar del silencio y la desmemoria y, que, sin embargo, demandan una denuncia constante que conlleve grandes cambios. El teatro de Tornero se identifica principalmente por su visión crítica sobre la realidad contemporánea. Profundiza en temas como la injusticia y la violencia y encuentra diferentes maneras dramáticas para interpretarlos. No le es suficiente una anécdota simple o unas injusticias contadas, sino que busca estructuras diversas para 
plantearlas. Controla la tensión dramática y maneja la capacidad de transmitir al espectador resentimiento, sufrimiento y denuncia.

La obra de Kalimat es un documento que cuenta en primera persona un conjunto de experiencias que se pueden percibir como consecuencia del empleo del arte al servicio de la comunidad y sus miembros. La función del teatro aquí consigue dimensiones que van más allá de su valor estético y su finalidad alcanza una cierta profundidad que lo conduce a mezclarse con otras disciplinas como, por ejemplo, la psicología y la sociología. Este campo interdisciplinario transforma el hecho dramático en algo más que una forma de expresión artística, convirtiéndolo en un lugar multidimensional donde cada persona de valorarse tanto a sí mismo como a su entorno.

Esta obra, que responde a los requisitos de las representaciones del psicodrama, nos ofrece la oportunidad de percibir y evaluar el empleo psicológico y social del teatro. Logra cumplir una doble misión tanto con los protagonistas como con los espectadores estimulando a ambos a intervenir de manera activa en la acción teatral emocionalmente mientras liberando a aquellos de sus negativas emociones con el objetivo de integrarlos de nuevo en la sociedad. De esta manera, el teatro reestablece su enfoque originario a medida que se acerca más a los orígenes del individuo y se convierte en agente de enlace del hombre con su realidad una vez facilitada su participación en la representación teatral.

Esta obra tiene como punto de partida los acontecimientos y los sucesos no ficticios; es decir, está basada y documentada en los testimonios de los refugiados, por lo que el grado de fidelidad histórica es muy importante. La finalidad de esta documentación reside en cumplir su misión de criticar la ocultación y el falseamiento de la realidad por parte de los políticos y sus medios de comunicación, convirtiendo así los episodios históricos en hechos sometidos a análisis con el fin de aclarar la desnuda verdad delante del público. 
La dramaturga, a través de esta obra dramática, sigue intentando realizar una mejor transformación en la sociedad siguiendo los pasos de los grandes escritores del teatro político y épico, a través de técnicas que le sirvan para realizar una denuncia política que critica el silencio de los responsables hacia las condiciones inhumanas de los sirios en los campos de refugiados. Al mismo tiempo, llama a la conciencia del público hacia el caso que estos están sufriendo, invitándole a participar activamente cuando salga del teatro, realizando diversas actividades para cambiar la realidad y mejorar la vida de los refugiados.

La utilización de los cantos dantescos añade un gran valor a esta composición documental puesto que mezcla unos versos clásicos con un conjunto de datos verdaderos, causando un cierto estado de desequilibrio al público cuya valoración de los acontecimientos dramatizados percibe unas dimensiones inalcanzables por medio de la fábula, dado que no queda nada por decir ni por hacer frente a la verdad. 


\section{Bibliografía:}

Arias, Luis Martín (2006): "La representación y el horror". Trama y Fondo: Revista de Cultura. VL - 21. Universidad de Valladolid (99-122)

Aristóteles (1974): Poética. Madrid: Gredos.

(1970): Política. Madrid: Instituto de Estudios Políticos.

Bello, María Carmen (2000). Introducción al Psicodrama. Guía para leer a Moreno. Ciudad de México. Colibrí.

Blatner, Adam (2005): El psicodrama en la práctica. Ciudad de México. Pax editorial.

editorial.

(2009): Bases del psicodrama. Ciudad de México. Pax

(2013): "Fundamentos teóricos del psicodrama (Pensamientos recientes)". TEP. Psicoterapia y Psicodrama. Vol. 2, núm. 1, 2013. Págs. 32-44.

Brecht, B (2004): Escritos sobre teatro. Madrid. Alba.

Castillo, Beliza (2013): "Psicodrama, Sociodrama y Teatro del Oprimido de Augusto Boal: Analogías y Diferencias". Teatro: Revista de Estudios Culturales. Núm. 26, primavera 2013: Augusto Boal Revisitado. Págs. 118- 139. Universidad Central de Venezuela.

Castri, Massimo (1978): Por un teatro político Piscator, Brecht, Artaud, Madrid, Akal.

Cattermole Ordóñez, Carlota (2018): “La 'Divina Comedia' “a contrapelo" en la obra de Peter Weiss: 'DC-Projekt' y 'Estética de la resistencia". Universidad Complutense de Madrid. Tenzone 13, 2018, (177-210)

Crispino, Danilo Tenorio (2007): "Reflexiones sobre el distanciamiento brechtiano". Ensayos Temáticos. Vol. 1 núm. 1 julio-diciembre de 2007, Págs. 21-24.

Escobar, Aliber (2016): "El Distanciamiento Brechtiano en las Obras de Michael Haneke". Revista Xihmai XI (21), 45-64, enero junio 2016. Universidad La Salle Pachuca. México.

Figueroa C., Gustavo (2013): "Freud, Breuer y Aristóteles: catarsis y el descubrimiento del Edipo". Revista chilena de neuro- 
psiquiatría. versión On-line.vol.52 no.4 Santiago dic. 2014. (consultada 23 abril 2020)

Herrera, José Francisco Moreno (2003): Teatro Mexicano de la Frontera. Universidad de Texas.

Mercader Larios, Concha (2013): "Teoría y técnica del psicodrama", Apuntes de Psicología 2013. Vol. 31. Núm. 3. Págs. 321-325.

Moreno, J.L. (1940): "Mental Catharsis and the Psychodrama". Sociometry. Vol. 3. Núm. 1. Págs. 220-238.

(1946). Psychodrama. First Volume. (Cuarta edición: 1972). Ambler, PA (1985): Beacon House.

Rimé, Bernard (2009): "Emotion Elicits the Social Sharing of Emotion: Theory and Empirical Review". Emotion Review, a new journal of ISRE (International Society for Research on Emotion), SAGE Publishing. New York.

Rodrigo Buron, Dulcinea (2013): "El origen del teatro épico. Fundamentos para una práctica revolucionaria" Scientia Helmantica. Revista Internacional de Filosofía. Núm. 1, marzo de 2013. Págs.137-163.

Rojas Bermúdez, J. (1997): Teorías y técnicas psicodramáticas. Barcelona. Paidós.

Sabater, Valeria (2018): El significado de la catarsis en psicología. 27 noviembre, 2018. https://lamenteesmaravillosa.com/elsignificado-de-la-catarsis-en-psicologia/ (consultado 30 de abril 2020)

Tornero, Helena: "Kalimat' és un drama humà d'unes dimensions difícils d'imaginar'. $\quad 07.02 .2017 \quad$ Empordà https://www.emporda.info/cultura/2017/02/07/helena-tornerokalimat-drama-huma/344691.html (consultado 1 de marzo 2020) Trancón, Santiago (2006): Teoría del teatro: bases para el análisis de la obra dramática, Madrid: Fundamentos. 